\title{
Estetik diş hekimliğinde renk seçimi
}

\author{
Görkem Sengez(0000-0002-7127-109X) ${ }^{\alpha}$, Can Dörter(0000-0001-5380-000X) ${ }^{\alpha}$ \\ Selcuk Dent J, 2019; 6: 213-220 (Doi: 10.15311/selcukdentj.430209)
}

Bašuru Tarihi: 03 Haziran 2018 Yayına Kabul Tarihi: 11 Temmuz 2018

\section{Öz \\ Estetik diş hekimliğinde renk seçimi}

Günümüzde ilerleyen teknolojiye bağlı olarak hastalar diş hekimine sıklıkla estetik restorasyon talebi ile başvurmaktadır. Bir diş hekiminin hastasına estetik bir görüntü sunabilmek amacıyla yapacağı restorasyonda dikkat etmesi gereken en önemli unsurlardan biri restorasyonun rengidir. Rengin bağlı olduğu üç faktör vardır; gözlemci obje ve ışık kaynağı. Bu üç faktörden herhangi biri değişirse, rengin algılanması da değişir.

Rengin özelliklerini anlatmak için çeşitli sistemler geliştirilmiştir. Munsell Renk Sistemi en çok kullanılan sistemlerdendir. Bu sistemde rengin hue, value ve chroma olmak üzere üç boyutu bulunmaktadır. Hue rengin kendisini (yeşil, kırmızı, mavi gibi), value parlaklığını, chroma ise yoğunluğunu ifade eder. CIELab ise rengi $L^{*}, a^{*}, b^{*}$ olarak üç eksende tanımlayan başka bir sistemdir.

Bir diş hekimi hastası için en uygun diş rengini seçmeli ve bu bulguyu teknisyene doğru aktarmalıdır. Renk seçimi görsel ve aletli renk seçimi olmak üzere ikiye ayrılır. Görsel renk seçiminde standart renk skalaları kullanılır. Bu yöntem subjektiftir ve kişiden kişiye değişebilir. Ayrıca gözlemcinin cinsiyeti, yaşı, kültürel geçmişi, göz yorgunluğu ve ortama bağlı faktörlerle de değișebilir. Ancak görsel renk seçimi halen diş hekimliğinde en sık kullanılan renk seçim yöntemidir. Daha estetik ve güvenilir sonuçlar elde edebilmek için aletli renk seçim yöntemleri geliştirilmiştir. Bu yöntemde spektrofotometre, kolorimetre ve dijital kameralar kullanılır. Bu cihazlar farklı şartlarda bile tutarlı sonuçlar verebilir ancak görsel yönteme kıyasla daha uğraştırıcı ve pahalıdır.

\section{ANAHTAR KELIMELER}

Dental restorasyonlar, diş estetiği, renk seçimi

Son yıllarda estetik konusu gitgide önem kazanmış ve hastaların estetik diş hekimliği konusundaki beklentileri artırmıştır. Estetiği sağlamak için yalnızca doğru formu elde etmek yetmez, aynı zamanda renk uyumunu da sağlamak gerekir. Dişlerin formu belli kurallara uygun olarak hazırlanabilir, ancak renk konusunda belirli kurallar ve ortak bir terminoloji yoktur. ${ }^{1}$ Renk seçimi subjektiftir ve diş hekimleri arasında farklılık gösterir. Farklı zamanlarda aynı diş hekiminin farklı seçimler yapması da mümkündür. ${ }^{2}$

Estetik restorasyonları yaparken doğru rengi seçmek yalnızca diş hekimleri için değil, gülüşünü güzelleştirmek isteyen hastalar için de önemli bir

\section{ABSTRACT}

\section{Shade matching in esthetic dentistry}

Today, due to advancing technology, patients often apply to the dentist for aesthetic restoration. One of the most important elements that a dentist should pay attention to in order to present an aesthetic image to his patient is the color of the restoration.Shade depends on three factors; the observer, the object, the light source. If any of these factors change, perception of color will change as well.

Many systems have been used for explaining the properties of color. Munsell Color System is widely used and consists of three dimensions: hue, value and chroma. Hue describes the family of the color such as green, red, blue. Value is the lightness and chroma is the intensity of the color. CIELab is another system which describes color in three axis which are called $L^{\star}, a^{\star}$ and $b^{*}$.

There are two ways of shade matching: visual and instrumental. A dentist is responsible for determining the most accurate color for the patient and communicate with the technician. Standardized shade guides are used in visual shade matching. This method is rather subjective and may vary from person to person. Also it may be affected by different factors such as age, gender and cultural background of the observer, eye fatigue and environmental factors. However visual shade matchingit is still the most frequently used shade matching method in dentistry. Instrumental shade matching methods were developed to achieve more reliable and esthetic outcomes. Sphectrophotometers, colorimeters and digital cameras can be used in this method. These devices give consistent results in different conditions, however they may be harder to apply and more expensive than visual method.

\section{KEYWORDS}

Dental restorations, dental esthetics, shade matching

olgudur. İngiltere'de yapılan bir araştırmaya katılan yetişkin populasyonunun yaşa bağlı olarak \% 12.1 15.5'inin dişlerinin görüntüsünden, \% 17.9-21.3'ünün de diş renginden memnun olmadığı ortaya çıkmıştır. ${ }^{1}$ ABD'de yapılan çalışmaya katılan yetişkin popülasyonun \% $34^{\prime}$ ü$^{3}$, Çin'de yapılan çalışmaya katılan popülasyonun \% 52.6'sı diş renginden memnun değildir. ${ }^{4}$

Diş hekimliğinde renk seçimi ikiye ayrılır: görsel ve bilgisayar destekli. Rengin görsel olarak değerlendirilmesi sübjektiftir. Günümüzde bu işlem renk skalaları ile yapılmaktadır. Bilgisayar destekli cihazlarla yapılan renk seçimi ise daha objektif

\footnotetext{
${ }^{\alpha}$ İstanbul Üniversitesi Diş Hekimliği Fakültesi Restoratif Diş Tedavisi Anabilim Dalı, İstanbul
} 
sonuçlar ortaya koymaktadır. Bu nedenle bu iki yöntemin birlikte kullanılması tavsiye edilir. ${ }^{5}$

Bu derlemenin amacı renk kavramı, renk sistemleri, günümüzde kullanılan renk seçim yöntemleri ve prensiplerinin detaylı bir şekilde anlatılmasıdır.

\section{RENK}

Renk, sıkça kullanılan fakat çoğunlukla yanlış aktarılan bir dildir. Estetik restoratif diş hekimliğinde renk seçimini başarıyla gerçekleştirebilmek için bu dili iyi bilmek gerekir. Bu zor bir görevdir, çünkü renk görsel ve bilimsel bileşenler içeren soyut bir kavramdır. Renk algılanmasında bireysel farklılıklar olabilir, zira göz, renk analizi için en güvenilir araç değildir. $^{6}$

Işığın değişik dalga boylarının gözün retinasına ulaşması ile ortaya çıkan algılamaya renk denir. Işığın maddelere çarptıktan sonra bir kısmının soğrulup bir kısmının yansıması nedeniyle algılamada çeşitlilik oluşur. Bu renk tonu olarak adlandırilır. ${ }^{7}$

Rengin oluşabilmesi için 2 şeye intiyaç vardır: bir uyaran ve bu uyaranı alıp değerlendiren bir yapı. Işık (uyaran) cisme çarpar, yansıyarak göze ve oradan beynin görme merkezine gider. ${ }^{8}$

Cisimleri görüp rengini söylememiz üzerlerine düşen ışığı yansıtmalarına bağlıdır. Işık olmadığında, renk de olmaz. Işık görünür bir elektromanyetik enerji olarak tanımlanır. ${ }^{9}$ Işık geçirmeyen temel renkler sarı, mavi ve kırmızı iken ışık spektrumundaki temel renkler kırmız, yeşil ve mavidir. ${ }^{10}$ Rengi, bütün dalga boylarının gözümüze aynı anda ulaşıı̆ı durumda beyaz, hiç ulaşmadığı durumda siyah olarak algıları. İnsan gözü elektromanyetik spektrumda dalga boyu 380 - 780 $\mathrm{nm}$ olan kısmı algılar. Bu yüzden bu kısma görünen Işık denir. ${ }^{11}$

Diş hekimliğinde Munsell Renk Sistemi ve CIE Renk Sistemi olmak üzere iki renk sistemi

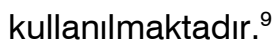

\section{Munsell renk sistemi}

Munsell renk sistemi en eski renk sistemidir. Albert H. Munsell tarafından 1905 yılında geliştirilmiştir. ${ }^{9}$

$\mathrm{Bu}$ renk sisteminde renkler, silindirik koordinatlar üzerinde gösterilmektedir (Şekil 1). Bu sistemdeki üç değişken hue, value ve chroma'dır. Value silindirin dikey ekseninde beyazdan siyaha kadar grinin tonlarını gösterir. Hue ise silindirin çevresindeki halka üzerinde yerleşmiştir ve beş ana, beş ara renge ayrımaktadır. Chroma ise yatay yönde ve merkezden dışarı doğru artmaktadır. ${ }^{12,13}$

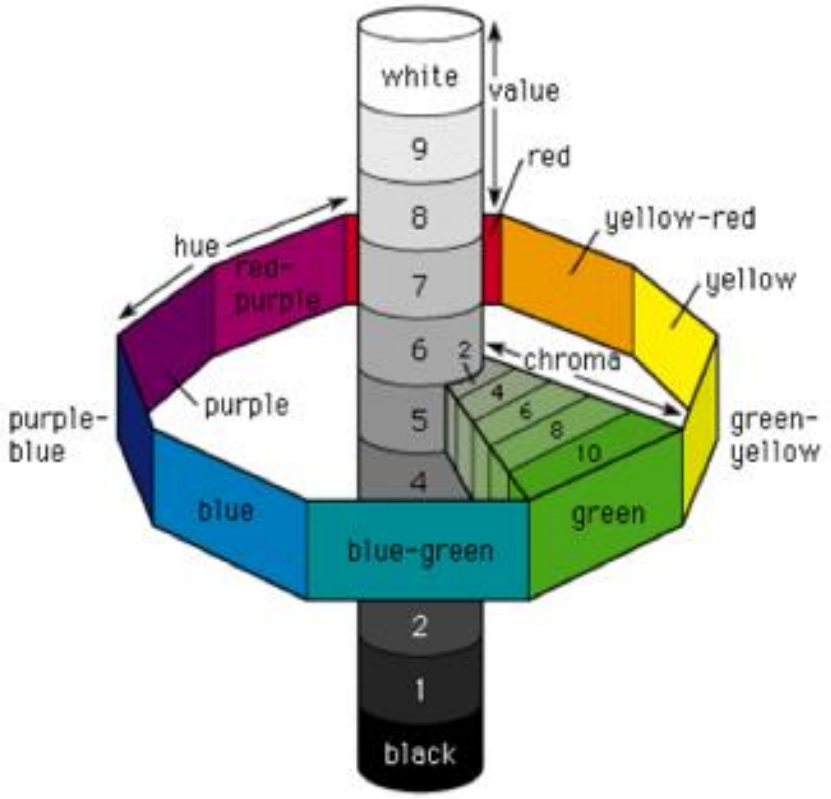

Şekil 1.

Munsell renk sistemi

Hue: Hue, ana renk olarak tanımlanır. Munsell, kendi sözleriyle: "bir renk ailesini diğerinden ayırmaya yarayan değerdir, sarıyı kırmızıdan, yeşili mavi veya mordan ayırmamızı sağlar" şeklinde ifade eder. ${ }^{14}$ VITA Classical renk skalasında A, B, C, D harfleriyle gösterilir. ${ }^{10}$

Value: Value, parlaklık olarak tanımlanır. Munsell'e göre value siyah-beyaz bir skaladır. Bu skalada 0 siyah, 10 beyazdır. Doğal dişin Value değeri 4 ila 8 arasında değişmektedir. ${ }^{15}$

Chroma: Ana rengin yoğunluğudur. Parlaklık ile ters orantılıdır. Chroma, Vita Classical renk skalasında numaralarla ifade edilir.., 10

\section{CIELAB renk sistemi}

Commission Intérnationale de l'éclairage tarafından 1976 yılında geliştirilen bu sistem, dental araştırma alanında gittikçe artan bir yaygınlıkta kullanılmaktadır. ${ }^{16,17}$ Munsell renk sisteminde olduğu gibi CIELAB Sistemi'nde de renk üç koordinatla tanımlanmaktadır: $L^{*}, a^{*}$ ve $b^{*}$ (Şekil 2). Value ve $L^{*}$ birbiriyle orantılıdır ve rengin aydınlığını, parlaklığını veya siyah/beyaz karakterini temsil eder. Rengin kromatik, veya siyah-beyaz olmayan karakterleri ise Munsell'de Hue ve Chroma ile temsil edilirken, bu sistemde $a^{*}$ ve $b^{*}$ ile temsil edilir. ${ }^{9}$

CIELAB Renk Sistemi, rengin tonundan bağımsız olarak 2 rengin yoğunluğu arasındaki mesafeye bağlı olmaksızın, iki rengin şiddeti arasındaki mesafenin algı şiddetine oranlanması yolu ile daha eşdeğer bir renk skalasına getirilmesini önerir. ${ }^{18}$ 


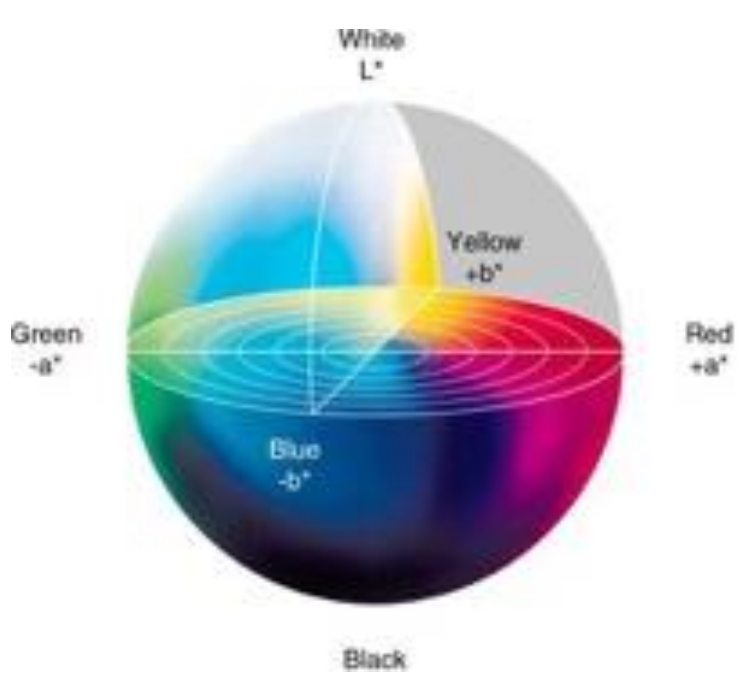

Şekil 2.

CIELAB renk sistemi

\section{MATERYALIN OPTIK ÖZELLIKLERI}

Bir objenin rengi sadece kullanılan renklendirme maddesi ve tonu ile değil, o objenin şeffaflı̆ı̆ (transparanlık), yarı şeffafığı (translusentlik) ve opaklığı ile de ilgilidir. Diş minesi ve dişi çevreleyen destek dokular yarı şeffaf dokulardır. ${ }^{19}$

\section{Opaklık}

Opaklık materyallerin ışığın geçmesine engel olma özelliği olarak bilinir. Bütün renkler absorbe edilmeden yansıyorsa obje beyazdır. ${ }^{19}$

\section{Translusentlik}

Translusentlik materyallerin ışığın geçişine kısmen izin vermesidir. ${ }^{19}$ Doğal dişler karakterizasyonunu çeşitli derecelerde translusentliğinden alır. Translusentlik, opaklık ve transparanlık arasında bir derece olarak ifade edilir. Genelde dişin translusentliğini artırmak parlaklığını azaltır; çünkü göze daha az ışık yansır. ${ }^{10}$

\section{Floresanslık}

Materyal tarafından ışığın absorbe edilerek uzun bir dalga boyunda yayılmasina floresanslık denir. Doğal dişler floresans özellik göstermektedir. ${ }^{10}$ Yapılan restorasyon ve doğal dişler farklı floresansa sahip olduğu takdirde renk uyumsuzlukları görülebilir. ${ }^{9}$ Floresans özellik gösteren restorasyonlar daha parlak olsa da pratikte floresans özelliğinin dental restorasyonlarda renk seçiminde önemli bir rol oynamadığı görülmüştür. ${ }^{20}$

\section{Opalesanslık}

Opalesans, materyalin ışık emildiğinde başka, ışık yansıdığında başka renk görünmesidir. Opaller prizma gibi davranır ve değişik dalga boylarını farklı açılarda kırar. Kısa dalga boyları daha çok kırılır. Minedeki hidroksiapatit kristalleri de prizma gibi davranır. Işığın dalga boyları dişler ve dental materyallerde değişik derecelerde opalesanslık içerir. Üzerine ışık düştüğünde opaller ve mine kırmızıları geçirir, mavileri de saçar; böylece mine esasen renksiz olsa da mavimsi görünür. Minenin opalesans özelliği dişi aydınlatır ve dişe optik derinlik ve canlılık katar. ${ }^{21,22,23,24}$

\section{Parlaklık}

Yüzey parlaklığı objeye cilalı bir görünüm kazandıran optik bir özellik olup rengin algılanmasında önemlidir. ${ }^{25}$ Pürüzsüz yüzeylerde yüksek parlaklık elde etmek mümkündür. Düzgün ve cilalı yüzeylerde gelen ışığın açısı yansıyan ışığın açısına eşitken, pürüzlü yüzeylere gelen ışın yüzey tarafından dağıtııı ve parlaklığında bir azalma olur. ${ }^{26}$

\section{Metamerizm}

Metamerizm, bir ışık kaynağında belirlenmiş bir cismin renginin diğer bir ışık kaynağı altında farklı görünmesidir. Belirli aydınlatma koşulları arasında benzer görünen ancak spektral yansıması farklı olan iki renge metamer, bu fenomene metamerizm denir. Metamerizm, laboratuvar ve dental klinik arasındaki aydınlatma farklılıklarından da kaynaklanabilir. Metamerizm sorunu renk seçimi ve doğrulamasının doğal gün ışığı ve floresan lamba gibi değişik aydınlatmalar altında yapılması ile çözülebilir. ${ }^{9}$

\section{Dişlerin renk özellikleri}

Yeni sürmüş olan dişler opak, tebeşirimsi bir görünüme sahiptir. Bunun sebebi yüzeyel mine tabakasının organik içeriğinin fazla, minerallerin az ve aralarının boşluklu oluşudur. Bu yüzeyel tabaka aşındıkça alttan daha az opak bir tabaka çıkar. Yaşlanma ile birlikte incelen mine, alttaki dentini daha fazla yansıtır. Minenin en ince olduğu kole bölgesinde renk yoğunluğu daha fazlayken, insizale doğru mine kalınlaştığı için yoğunluk da azalır. ${ }^{10}$

Yaşlı dentin daha koyu ve yeşil-mavi tonları ağırlıklı iken genç dentin daha sarı-kırmızıdır. Pulpa odası genç dişlerde daha büyük olduğu için dişe kırmızılık katar. Aynı arktaki dişler farklı renk ailelerine ait olabilir. Örneğin yeşilden kırmızıya doğru artan $a^{*}$ değeri sırasıyla en yüksek kanin (en kırmızı), sonra santral ve lateralde görülür. Maviden sarıya doğru artan $b^{*}$ değeri ise sırasıyla en yüksek kanin (en sarı), sonra lateral ve santraldedir. Doğal dişlerin hue ve chroma değerleri sabit değildir. Bu nedenle restorasyonlar yapilırken farklı renkte restoratif materyallerin bir arada kullanılması gerekebilir. ${ }^{10}$

\section{RENK SEÇiMi}

Diş hekimliğinde renk seçimi 2 çeşittir: Görsel renk seçimi ve Aletli renk seçimi. ${ }^{27}$ 


\section{Görsel renk seçimi}

Hastanın dişi ve skalanın karşılaştırılması ile yapılan görsel renk seçimi klinik diş hekimliğinde en sık başvurulan yöntemdir (Şekil 3). ${ }^{27}$

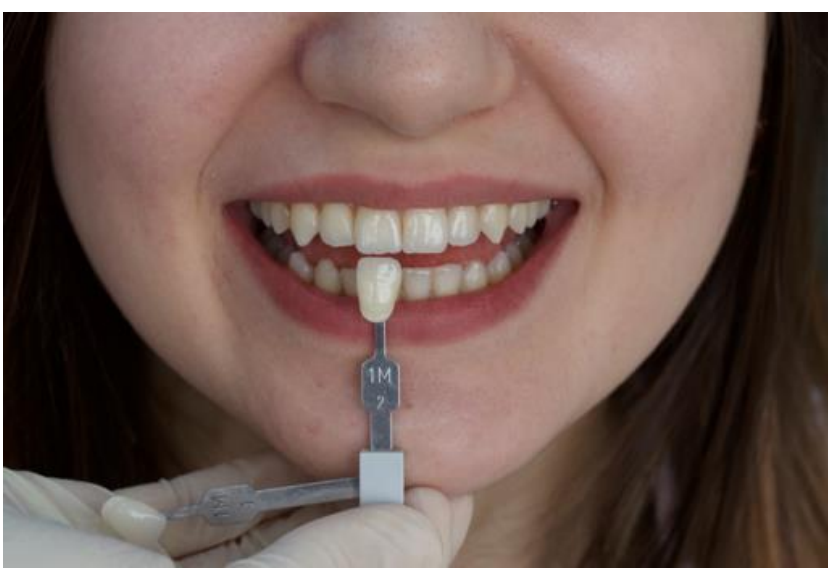

Şekil 3.

Görsel renk seçimi

Gözle yapılan renk karşılaştırmaları bireyler arası renk algılamadaki farklılıklardan dolayı tutarsız ve güvenilmez bulunmaktadır. Gözlemcinin uyarana verdiği psikolojik ve fizyolojik cevaplara bağlı olarak değişir. Tutarsızlıklar yorgunluk, yaşlanma, duygular, göz, obje ve aydınlatma pozisyonu, metamerizm ve dişin yüzey yapısı gibi faktörlere bağlıdır. ${ }^{28,29}$

Bunun dışındaki diğer dezavantajlar, diş hekimi ile diş teknisyeni arasındaki iletişimde standardizasyonun sınırlı olması, farklı diş hekimleri arasında veya diş hekiminin kendi renk seçimleri arasında değişikliklerin olması ve çıkan sonuçların CIELab birimine dönüştürülememesi olarak sayılabilir. ${ }^{27,30}$ Yukarıda bahsedilen tüm sorunlara rağmen görsel renk seçimi halen diş ve restorasyonların rengini tayin etmek için kullanılan birincil yöntemdir. ${ }^{31}$

\section{Renk skalaları}

Klinik diş hekimliğinde renk seçimi hastanın dişinin standart bir renk skalası ile karşılaştırma esasına dayanır. ${ }^{27}$

Illk sistematik renk skalası Clark tarafından üretilen 'Tooth Color Indicator' olup 60 seramik örnek içermektedir. Sonrasında birçok ürün piyasaya sürülse de esas devrim 1950'lerin ortalarında satışa çıkarılan 'Vitapan Classical' (VC, Vita Zahnfabrik, Bad Sackingen, Germany) renk skalasıyla gerçekleşmiştir. Bir sonraki gelişme 1990'ların sonlarında 'Toothguide 3D-Master (TG, Vita Zahnfabrik, Bad Sackingen, Germany)'ın geliştirilmesiyle yaşanmıştır. Son olarak 'VITA Linear Guide 3D Master' (Vita Zahnfabrik, Bad Sackingen, Almanya) renk skalası da kullanıma sunulmuştur. ${ }^{32}$

\section{Vitapan Classical (Vita Lumin Vacuum)}

1956 yılında piyasaya sürülen Vitapan Classical renk skalasında 16 renk örneği hue değeri göz önüne alınarak dizilmiştir (Şekil 4). Skaladaki hue gruplandırılması harflerle:

- A: sarı - kırmızı

- B: sarı

- C: gri

- D: kırmızı - sarı - gri

Chroma gruplandırılması rakamlarla (A1, B3, D4 şeklinde) belirtilmiştir. Bu skala kullanılırkan ilk önce hue, daha sonra chroma, en son value eşleştirilmesi yapılır. ${ }^{16,33}$

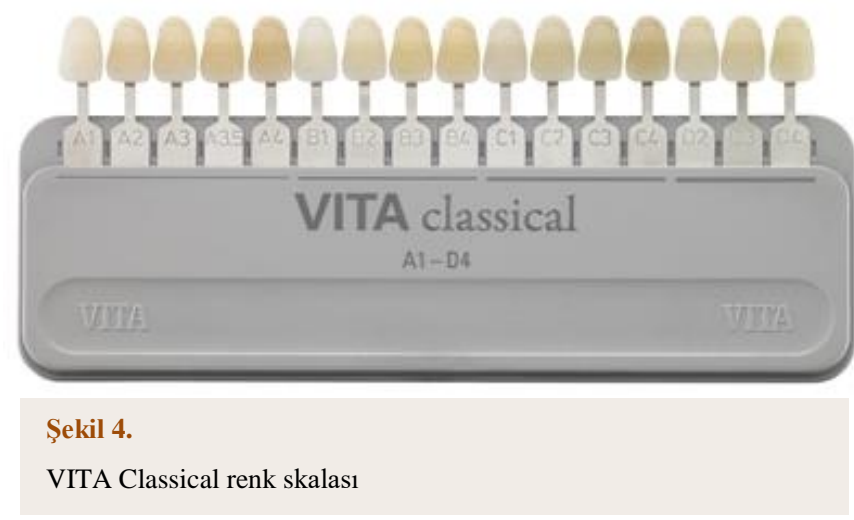

\section{VITA Toothguide 3D-Master}

VITA Toothguide 3D-Master Renk Skalası Value değeri alınarak tasarlanmıştır. Bunun sebebi ise rengin içerdiği gri tamamlayıcıların miktarı olan aydınlık, yani value değerinin belirlenmesinin hue değerine kıyasla çok daha önemli olmasıdır. Bu skalada toplam 26 adet renk anahtarı bulunmaktadır (Şekil 5). Vitapan Classical ile karşılaştırıldığında VITA Toothguide'ın doğal dişlere daha iyi uyum sağladığı, geniş renk çeşitliliğine sahip olduğu ve renklerin daha uniform olarak dağıldığı belirtilmiştir. ${ }^{34,35,36}$

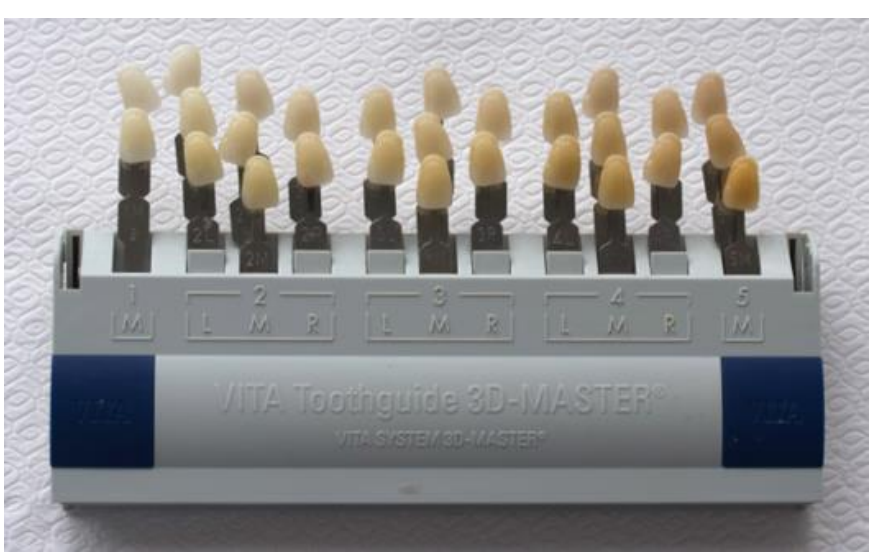

Şekil 5.

VITA Toothguide 3D-Master renk skalası 


\section{Kompozit renk skalaları}

Renk seçiminde kullanılan gerek kompozit, gerekse porselen skalalarının renk dağılımları doğal dişlere göre yetersizdir. ${ }^{36,37,38}$ Renk skalaları genellikle kompozit materyal yerine doldurucusuz metakrilattan yapıldıklarından dolayı, kompozit rezinin polimerizasyon sonucu oluşan rengi kompozitin gerçek rengini, translusentliğini veya opasitesini doğru biçimde yansıtmamaktadır. ${ }^{39} \mathrm{Bu}$ nedenle klinikte renk seçimini basitleştirmek için üreticiler restoratif materyallerin renklerini, yaygın olarak kullanılan Vita Lumin renk skalasına uyumlu hale getirmişlerdir (Şekil-6). Böylece yapılan porselen restorasyonlarla uyumlu renkte kompozit rezin uygulamaları yapılabilmekte ve renklerin değişken olduğu farklı renk skalalarına gereksinim azalmakta, uygulayıcılar arasındaki iletişim düzelmektedir. ${ }^{40}$

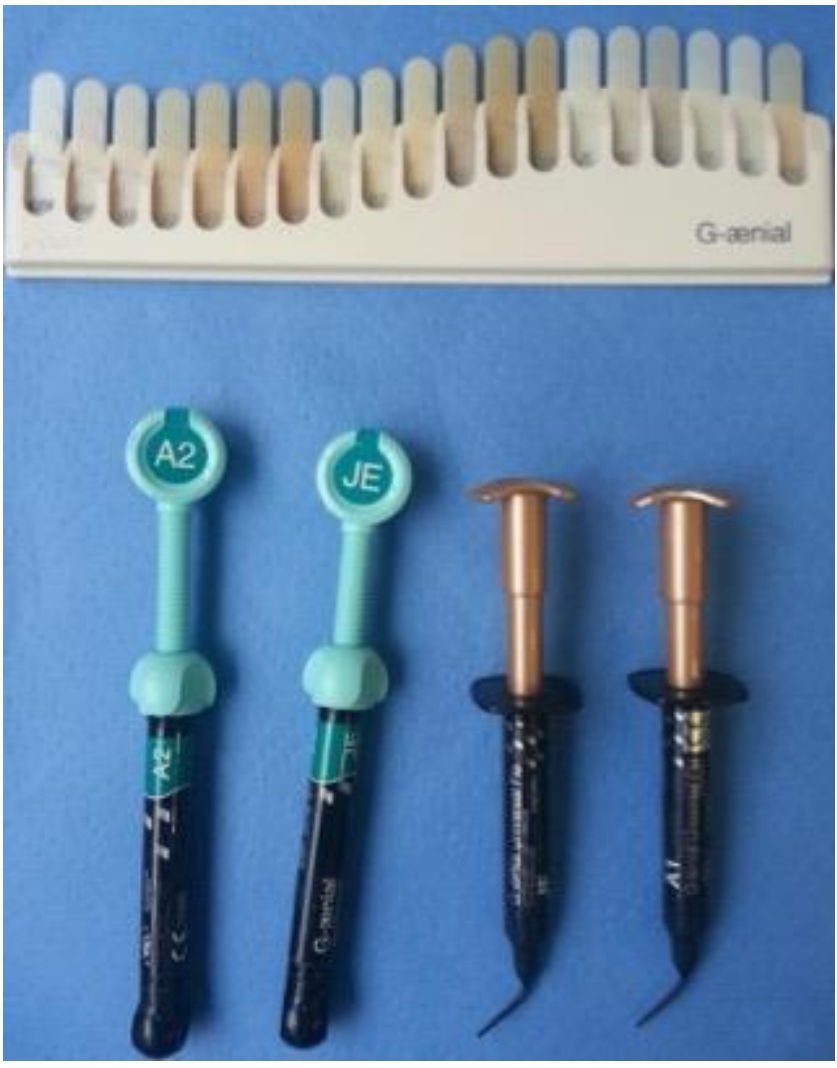

Şekil 6.

GC Europe'un Gaenial kompozitler için hazırladığı renk skalası

Saraç ve ark. (2005) yaptıkları bir araştırmada değerlendirilen kompozit materyallerin Vita Lumin renk skalası ile arasında gözle görülebilir ve klinik olarak kabul edilemeyen renk farklılıklarının mevcut olduğunu bildirmişlerdir. Kompozit restorasyonların renk seçiminde Vita Lumin renk skalasının kullanılması klinik olarak kabul edilemeyecek sonuçlar doğurabileceğinden, renk seçiminde kompozit materyale ait renk skalası veya bu materyalden yapılmış özel bir renk skalasının kullanılmasının daha uygun olacağı sonucuna varılmıştır. ${ }^{41}$

\section{YARDIMCI ISSIK KAYNAKLARI}

Diş hekimi muayenehanelerindeki ışık koşulları mevsime, günün saatine, odadaki ışığın tipine göre değişir. Çevresel ışığın etkisini en aza indirmek için elle tutulan yardımcı ışık kaynaklarının kullanılması önerilir. Bu aletlerin ilk tiplerinde floresan tüpler kullanılmış, çok büyük ve kullanımının zor olması nedeniyle bazı iyileştirmeler yapılma ihtiyacı doğmuştur. İlerleyen yıllarda daha pratik ve kullanımı kolay aletler piyasaya sunulmuştur. ${ }^{42}$ Curd ve ark (2006) yaptıkları çalışmada ışık düzeltici alet altında yapılan renk seçimlerinin günışığı altında yapılanlara göre daha doğru olduğunu bulmuştur. Bu nedenle görsel renk seçiminde piyasada bulunan Demetron Shade Light (KerrHawe, Bioggio, Switzerland) ve Smile Lite (Smile Line, Switzerland) (Şekil-7) gibi ışık düzeltici aletlerden yararlanılabilir. Bu aletler $5500 \mathrm{~K}$ $6500 \mathrm{~K}$ aralığında doğal gün ışığı sağlamaktadır. ${ }^{43}$

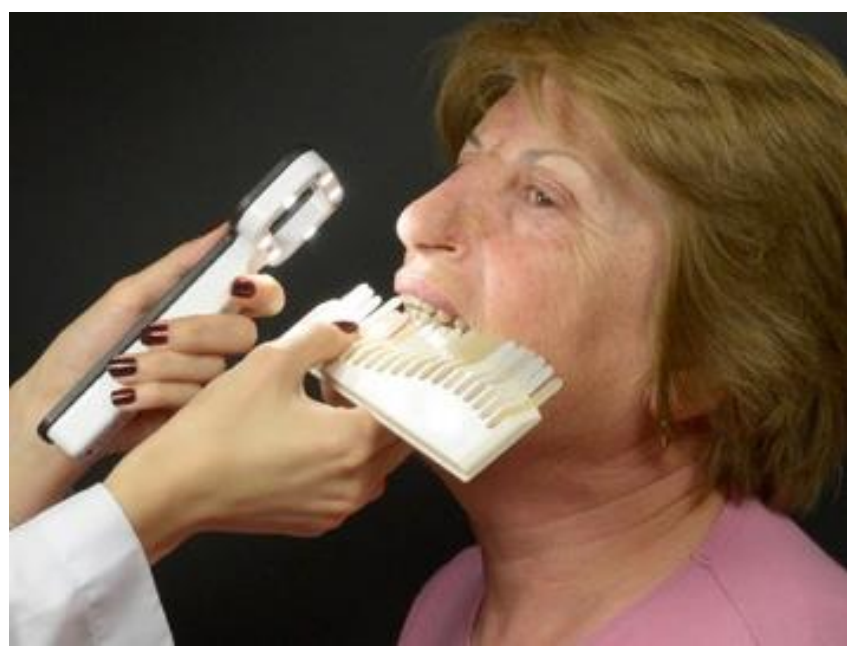

Şekil 7.

Smile Lite ile renk seçimi

\section{ALETLI RENK SEÇIMI}

Diş hekimliği dünyasına girdiklerinden beri spektrofotometreler ve kolorimetreler daha çok araştırmalarda kullanılmış, günlük klinik kullanımda yerini almamıştır. $\mathrm{Bu}$ aletler rengin $\mathrm{CIE} L^{*} a^{*} b$ renk parametreleri cinsinden değerini verir ve iki renk arasındaki farkın sayısal olarak hesaplanmasına olanak sağlar. Aletli renk analizi sonuçları objektiftir, ölçülebilir ve hızla elde edilebilir. ${ }^{44}$

Aletli renk ölçümü şu aletlerle yapılır:

a.RGB Cihazları: Kırmızı, mavi, yeşil görüntü datalarını renk görüntüsüne dönüştürür. Ancak ayrıntılı bir sonuç vermez. ${ }^{30}$

b.Dijital Kameralar: Son yıllarda hekim-teknisyen iletişiminde kullanımı oldukça artmıştır. En büyük avantajı sadece bir noktanın değil tüm objenin renginin kaydedilmesidir. ${ }^{30}$

Dijital kameralar dişin üzerindeki efektlerin, örneğin mine hipoplazileri, dekalsifikasyonlar ve 
translusentliğin varlığında klinisyen ve teknisyen arasında aktarımın doğru olarak yapılabilmesi için kullanılmalıdır. Ayrıca dijital görüntülerin elektronik olarak Internet üzerinden gönderilebilmesi de bu yöntemin avantajlarından bir tanesidir. ${ }^{45}$

c.Kolorimetreler: Kolorimetreler CIELAB biriminde ( $L^{*}$, $\left.a^{\star}, b^{\star}\right)$ sonuç verir. Kolorimetreler matematiksel işlem olmaksızın direkt renk koordinatlarını verir. ${ }^{46}$

Ancak kolorimetreler tamamen hatasız sonuç vermez. Seghi, kolorimetre ile alınan dataların porselen translusensliği ile büyük oranda değişebileceğini belirtmiştir. ${ }^{46}$

d.Spektrofotometreler: Spektrofotometreler görülebilir spektrumun üzerinde her dalga boyunda yansıtılan ışığın miktarını ölçerler. Renklerin sayısal değerlerini verirler. Spektrofotometreler diş hekimliğinde renk analizi ve seçimi konusundaki en kesin, kullanışlı ve esnek aletlerdir (Şekil 8). ${ }^{48}$

Gehrke ve ark. görsel renk seçimi ile spektrofotometre ile dijital renk seçimi yöntemlerini karşılaştırmış, ikinci yöntemle elde edilen sonucun daha tekrarlanabilir ve güvenilir olduğunu belirtmiştir. ${ }^{49}$ Spektrofotometrelerden elde edilen data diş hekimleri ve diş teknisyenlerinin faydalanabileceği formata dönüştürülmelidir. Aletlerden elde edilen ölçümler genellikle dental renk skalaları eşleniğine dönüştürülür. ${ }^{50}$

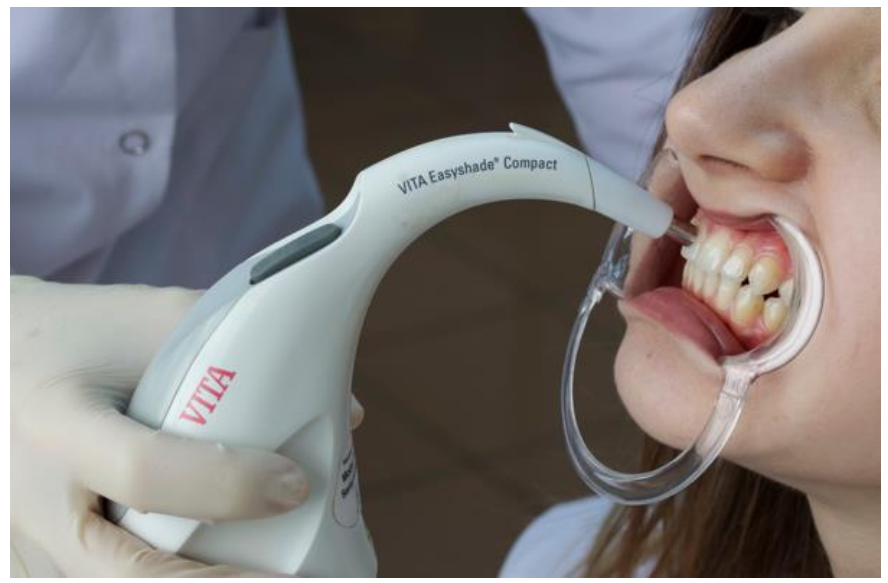

Şekil 8.

VITA Easyshade ile renk seçimi

\section{RENK SEÇIMINDE GENEL PRENSIPLER}

1. Hasta pencerenin karşısına, başı dik olarak oturtulur. Hekim, hasta ile pencere arasında yer alır.

2. Hastanın ve hekimin gözü aynı hizada olmalıdır. Böylece hekim gözlem sırasında retinanın renk hassasiyeti en yüksek olan reseptörlerini kullanılır.

3. Renk seçimi farklı aydınlatma koşulları altında tekrarlanmalıdır. İlk seçim pencere kenarında ve gün ışığında yapılır. Sonrasında floresan ışık ve ampul ışığı altında doğrulanır.
4. Karşılaştırma yapılacak diş temiz olmalıdır. Gerekli durumlarda diş üzerindeki lekeler polisajla giderilir.

5. Renk karşılaştırmaları hasta randevusunun en başında yapılmalıdır. Diş kurudukça value değeri artar (özellikle lastik örtü kullanımı esnasında).

6. Hasta parlak renkli kıyafetlerden kaçınmalı, varsa rujunu temizlemelidir.

7. Çalışma odasının duvarları parlak olmayan, mat renklerle boyanmış olmalıdır.

8. Renk seçimi öncesinde göz gri-mavi bir yüzeye sabitlenerek dinlendirilmelidir. $\mathrm{Bu}$, retinadaki tüm renk sensörlerini dengeler ve gözü dişin sarı rengine karşı hassaslaştırır.

9. Ana rengi belirlemekte şüpheye düşülüyorsa $A$ grubundan bir renk seçilmelidir. Çünkü dişlerin $\%$ 80'i A grubundadır.

10.Kole rengi saptanırken iç dudak yukarı kıvrılır. Bu sırada insizal kenar kapatılır. İnsizal renk seçimi hasta konuşurken veya gülümserken yapılır.

11.Diş rengi kısım kısım belirlendikten sonra tespit edilen renklerin uyumu son kez genel olarak kontrol edilir.6,9,51,52

\section{SONUÇ}

Estetik diş hekimliğinde restorasyon başarısını etkileyen en önemli faktörlerden birisi renktir. Restorasyonun renginin komşu dişlerle uyumlu olması daha doğal bir görüntü sağlayacaktır. Renk seçimi yapılırken renge etki eden etmenler göz önünde bulundurulmalı ve ideal koşullar oluşturulmalıdır. Klinik uygulamada hem aletli, hem de görsel renk seçiminin kombine kullanılması en doğru sonucu verecektir. 


\section{KAYNAKLAR}

1. Alkhatib MN, Holt R, Bedi R. Age and perception of dental appearance and tooth colour. Gerodontology 2005; 22.1: 32-6.

2. Culpepper WD. A comparative study of shadematching procedures. J Prosthet Dent 1970; 24.2: 16673.

3. Odioso LL, Gibb RD, Gerlach RW. Impact of demographic, behavioral, and dental care utilization parameters on tooth color and personal satisfaction. Compendium of continuing education in dentistry. Jamesburg, NJ 2000; 29(suppl.): 35-41.

4. Xiao J, Zhou XD, Zhu WC, Zhang B, Li JY, Xu X. The prevalence of tooth discolouration and the selfsatisfaction with tooth colour in a Chinese urban population. J Oral Rehabil 2007; 34(5): 351-60.

5. Bayındır F, Wee AG. [The use of computer aided systems in tooth shade-matching]. Hacettepe Dişhekimliği Fakültesi Dergisi 2006; 30(3): 40-6.

6. Chu SJ. [Color] Gürel G, editör. Porselen Laminat Venerler Bilim ve Sanatı. 1. Baskı. İstanbul: Quintessence Yayıncılık. 2004. p.160-82.

7. Strenk SA, Strenk LM, Koretz JF. The mechanism of presbyopia. Prog Retin Eye Res 2005; 24(3): 379-93.

8. Şen D, Gür H, Nayır(Pamuk) E. [Color in Dentistry]. Diş Hekimliğinde Klinik Dergisi 1996; 3: 139-44.

9. Wee AG. Description of Color, Color- Replication Process, and Esthetics. Rosenstiel SF, Land M, Fujimoto J. Contemporary Fixed Prosthodontic. 5th ed. CV Mosby Co. 2001. p.624-45.

10.Fondriest J. Shade Matching in Restorative Dentistry: The Science and Strategies. Int J Periodontics Restorative Dent 2003; 23: 467-79.

11. McPhee ER. Extrinsic Coloration of Ceramometal Restorations. Dent Clin North Am 1985; 29.4: 645-67.

12. Horn DJ, Bulan-Brady J, Hicks ML. Sphere spectrophotometer versus human evaluation of tooth shade. J Endod 1998; 24.12: 786-90.

13.Phillips RW. Skinner's Science of Dental Materials. 9th ed. Philadelphia: WB Saunders Comp; 1991. p. 47527.

14. Munsell AH. A color notation. 5th ed. New York: Munsell Color Comp; 1919.

15. Hammad IA, Stein RS. A qualitive study for the bond and color of ceramometals: Part II. J Prosthet Dent 1991; 65.2: 169-79.

16.Turgut $S$, Bagis $B$. Diş hekimliğinde renk ve renk ölçüm yöntemleri. Atatürk Üniv. Dis, Hek. Fak. Derg 2012; (Suppl 5): 65-75.

17.Seghi RR, Johnston WM, O'brien WJ. Spectrophotometric analysis of color differences between porcelain systems. J Prosthet Dent 1986; 56.1: 35-40.

18. Paravina RD, Powers JM. Esthetic color training in dentistry. 1st ed. St. Louis. Elsevier Mosby; 2004. p.165.
19. Craig GR. Restorative dental materials. 8th ed. St. Louis. The Mosby Inc; 1989.

20.Seghi RR, Johnston WM. Estimate of colorimetric measurement errors associated with natural tooth fluorescence, J Dent Res 1992; 71: 303.

21.Sundar V, Amber PL. Opals in nature. J Dent Technol 1999;16.8:15-17

22.Chu SJ. Use of a Reflectance Spectrophotometer in Evaluating Shade Change Resulting from Tooth-Whitening Products. J Esthet Restor Dent 2003; 15(1): 42-8.

23. Garber DA, Adar P, Goldstein RE, Salama H. The quest for the all-ceramic restoration. Quintessence Dent Technol 2000; 23: 27-36.

24. Ten Bosch JJ. Coops JC. Tooth color and reflectance as related to light scattering and enamel hardness. J Dent Res 1995; 74.1: 37480.

25.Lee YK, Bum-Soon L, Cheol-We K. Effect of surface conditions on the color of dental resin composites. J Biomed Mater Res 2002; 63.5: 657-63.

26. Obregon A, Goodkind RJ, Schwabacher WB. Effects of opaque and porcelain surface texture on the color of ceramometal restorations. J Prosthet Dent 1981; 46.3: 33040.

27.Van der Burgt TP, Ten Bosch JJ, Borsboom PCF, Kortsmit WJPM. A comparison of new and conventional methods for quantification of tooth color. J Prosthet Dent 1990; 63(2): 15562.

28.Lehmann KM, Devigus A, Igiel C, Wentaschek S, Sattati Azar M, Scheller H. Repeatability of color-measuring devices. Eur $\mathrm{J}$ Esthet Dent 2011; 6: 462-70.

29. Corcodel N, Helling S, Rammelsberg P, Hassel AJ. Metameric effect between natural teeth and the shade tabs of a shade guide. Eur $\mathrm{J}$ Oral Sci 2010; 118: 311-6.

30.Chu SJ, Devigus A, Paravina RD, Mieleszko AJ. Fundamentals of Color: Shade Matching and Communication in Esthetic Dentistry. 2nd ed. Hanover Park, IL: Quintessence Publishing Co., Inc.; 2010.

31.Dozic A, Kharbanda AK, Kamell H, Brand HS. European dental students' opinions about visual and digital tooth colour determination systems. J Dent 2011; 39: 23-8.

32.Paravina RD. Performance assessment of dental shade guides. J Dent 2009; 37: 15-20.

33. Brewer JD, Wee A, Seghi RR. Advances in color matching. Dent Clin North Am 2004; 48: 341-58. 
34.Trakyalı G. [Methods Used for Color Determination]. EÜ Dişhek Fak Derg 2013;34 (1): 1-10.

35.Paravina RD, Johnston WM, Powers JM. New shade guide for evaluation of tooth whitening-colorimetric study. J Esthet Restor Dent 2007; 19: 276-83.

36. Paravina RD, Majkic G, Imai FH, Powers JM. Optimization of tooth color and shade guide design. J Prosthet Dent 2007; 16: 269-76.

37. Schwabacher WB, Goodkind RJ. Three-dimensional color coordinates of natural teeth compared with three shade guides. J Prosthet Dent 1990; 64.4: 42531.

38. Shotwell, JL, Johnston WM, Swarts RG. Color comparisons of denture teeth and shade guides. $J$ Prosthet Dent 1986; 56.1: 31-4.

39.Swift Jr EJ, Hammel SA, Lund PS. Colorimetric evaluation of Vita shade resin composites. J Prosthet Dent 1994; 7(4): 356-61.

40. Ruyter IE, Nilner K, Möller B. Color stability of dental composite resin materials for crown and bridge veneers. Dent Mater 1987; 3(5): 246-51.

41.Saraç D, Saraç ŞY, Yüzbaşıŏlu E. [Color Differences Between Different Composites and a Shade Guide]. GÜ Dişhek Fak Derg 2005; 22(2): 77-82.

42. Gasparik C, Grecu AG, Culic B, Badea ME, Dudea D. Shade-matching performance using a new lightcorrecting device. J Esthet Restor Dent 2015; 27(5): 285-92.

43. Curd FM, Jasinevicius TR, Graves A, Cox V, Sadan A. Comparison of the shade matching ability of dental students using two light sources. J Prosthet Dent 2006; 96.6: 391-6.

44.Okubo SR, Kanawati A, Richards MW, Childressd S. Evaluation of visual and instrument shade matching. J Prosthet Dent 1998; 80(6): 642-48.

45. Vivek R, Singh A, Soni R, Singh SV, Chaturvedi TP. Conventional and digitally assisted shade matching A comparative study. Indian Journal of Dentistry 2013; 4(4): 191-9.

46. Seghi RR, Hewlett ER, Kim J. Visual and instrumental colorimetric assessments of small color differences on translucent dental porcelain. J Dent Res 1989; 68.12: 1760-4.

47.Seghi RR, Johnston WM, O'Brien WJ. Performance assessment of colorimetric devices on dental porcelains. J Dent Res 1989; 68: 1755-9.

48. Paul SJ, Peter A, Rodoni L, Pietrobon N. Conventional visual vs spectrophotometric shade taking for porcelain-fused-tometal crowns: a clinical comparison. Int J Periodontics Restorative Dent 2004; 24: 222-31.

49. Gehrke P, Riekeberg U, Fackler O, Dhom G. Comparison of in vivo visual, spectrophotometric and colorimetric shade determination of teeth and implant-supported crowns. Int J Comput Dent 2009; 12: 247-63.
50.Kielbassa AM, Beheim-Schwarzbach NJ, Neumann K, Zantner C. In vitro comparison of visual and computeraided pre-and post-tooth shade determination using various home bleaching procedures. J Prosthet Dent 2009; 101: 92-100.

51.Fischer J. Esthetics and prosthetics: an interdisciplinary consideration of the state of the art. Chicago. Quintessence Publishing Company. 1991.

52. Korson D, Druttman ACS. Aesthetic design for ceramic restorations. Chicago. Quintessence Publishing Company. 1994.

Yazışma Adresi:

Görkem SENGEZ

İstanbul Üniversitesi

Diş Hekimliği Fakültesi

Restoratif Diş Tedavisi AD

Çapa, Fatih, İstanbul

Tel : : +905367489629

E-mail : gorkemsengun@gmail.com 